\title{
TUBERCULOSIS OF THE SPINE
}

\section{Associated with pneumoconiosis complicated by progressive massive fibrosis}

\author{
By W. J. Stanley, M.B., Ch.B. \\ Medical Registrar
}

A. Thelwall Jones, M.D., M.R.C.P.

Consultant Physician, Whitton Hospital

Recent work has suggested that the condition of progressive massive fibrosis complicating coal workers pneumoconiosis is a tuberculous infection modified by the presence of coal dust in the lungs (Gibson and Kilpatrick, 1955).

The following case report may be of interest in that the patient developed a tuberculous bone lesion in addition to progressive massive fibrosis.

\section{Case Report}

The patient, Mr. J. B., a coal-miner, aged 57 years, was admitted to hospital on July I, 1955 .

His illness began in December 1954, with severe upper abdominal pain, which remained more or less constant for a month and then gradually

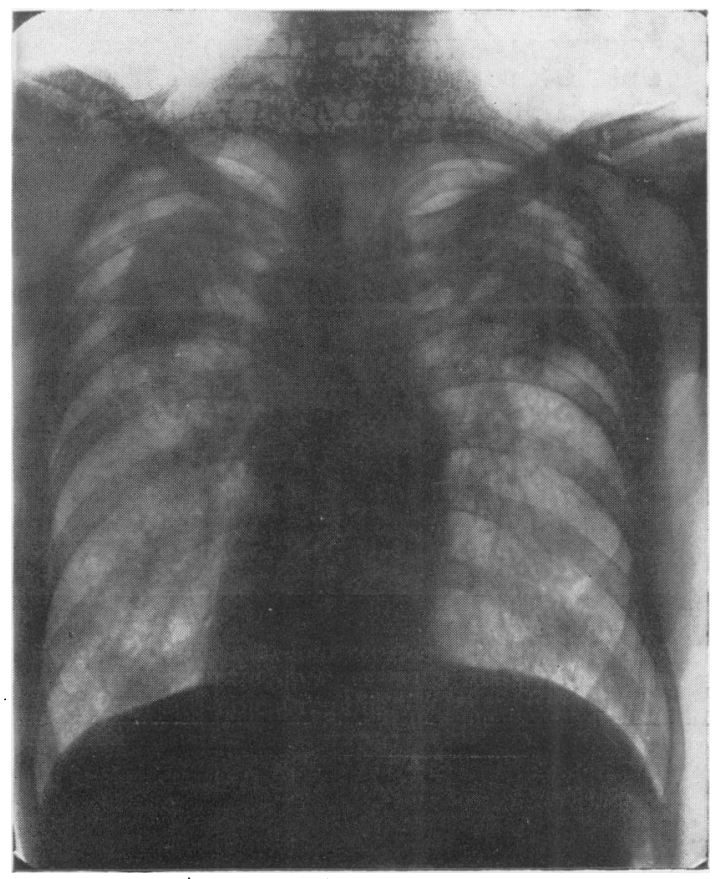

FIG. I.-Chest X-ray (antero-posterior view) showing pneumoconiotic changes with massive shadowing in both sub-apical regions. disappeared, to be replaced by pain in the lower dorsal region. This latter pain was aggravated by movement and relieved by lying down, and had been present ever since, finally forcing the patient to remain in bed.

A chronic cough had been present for the past ten years, with increasing dyspnoea on exertion. There had never been any haemoptysis.

Since 1920, he had worked as a collier in mines in different parts of the country, but had not been absent from work until his present illness. The only previous illness of note was lobar pneumonia in 1919.

There was no family history of tuberculosis.

His general practitioner referred him to

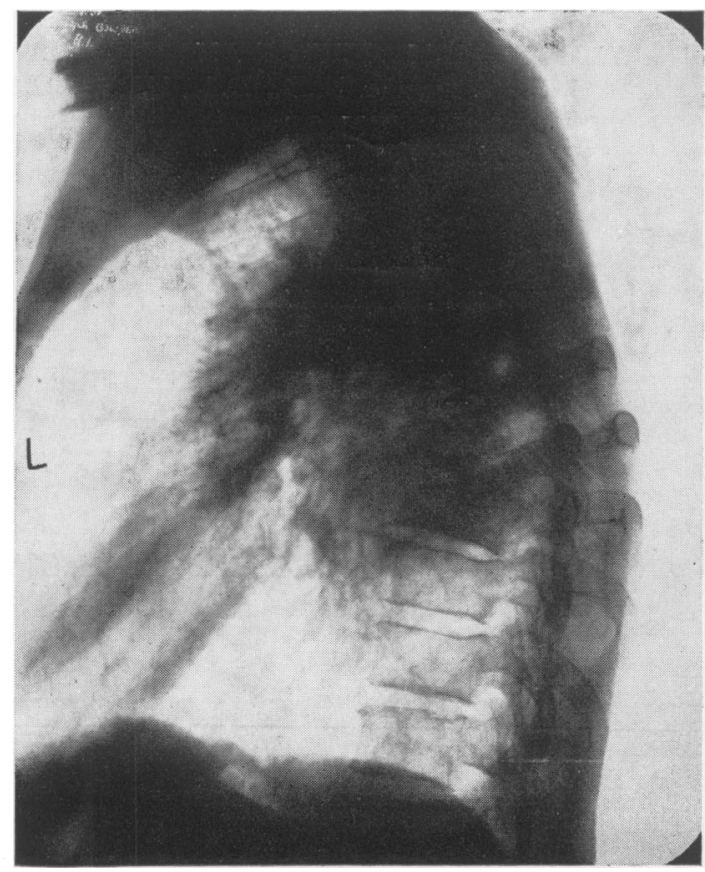

FIG. 2.-Lateral X-ray of the spine showing collapse of the body of $\mathrm{D} 9$ and partial collapse of the body of D 8 . 
another hospital for investigation, and a barium meal was carried out in January 1955. This was normal. He continued to attend for X-rays of spine and chest as an out-patient and was finally admitted to the chronic ward of this hospital with a diagnosis of spinal secondaries, primary site unknown.

On examination, his general condition was fairly good. There was an angular deformity of the dorsal spine at the level of D 9. The chest was emphysematous. Clinical examination did not reveal any other abnormality. There was no evidence of spinal cord involvement.

Chest X-ray showed pneumoconiosis with massive shadowing in both upper lobes (Fig. I). Both halves of the diaphragm moved well on screening. X-rays of the dorsal spine showed that the intervertebral disc between $\mathrm{D} 8$ and $\mathrm{D} 9$ had been destroyed, with collapse and fusion of these two vertebrae (Fig. 2). A large paravertebral abscess was evident.
Reviewing the previous X-rays of the spine, the first changes were narrowing of the disc space between $D 8$ and D 9 , and anterior wedging of the body of $\mathrm{D}$ 9. There had been no significant change in the radiological appearance of the chest.

The results of other investigations were as follows:

Mantoux reaction ( $1 / 1,000)$-positive.

Serum acid phosphatase-1.7 units per cent. (King-Armstrong units).

Haemoglobin 95 per cent.

Leucocytes 6,700 per c.mm.

(Polymorphonuclears 4,000; lymphocytes 2,350 , monocytes $35^{\circ}$ per c.mm.)

A diagnosis of tuberculosis of the spine was made and he was transferred to a sanatorium for treatment.

\section{BIBLIOGRAPHY}

GIBSON, J. C., and KILPATRICK, G. S. (1955), Brit. med. $\mathcal{f}$., i, 994 .

\section{ANAESTHETICS \\ (Special number of Postgraduate Medical Journal, September, 1955)}

Price: 3s. 10d. post free

THE MODERN VIEW OF ANAESTHESIA

G. S. W. Organe, M.D., D.A., F.F.A.R.C.S.

THE PRODUCTION OF

UNCONSCIOUSNESS

B. G. B. Lucas, D.A., F.F.A.R.C.S.

\section{ANALGESIA}

J. B. Wyman, M.B.E., D.A., F.F.A.R.C.S.

MUSCLE RELAXATION IN SURGERY

Angus Smith, F.F.A.R.C.S.

CONTROL OF THE BLOOD PRESSURE

AND CONTROLLED HYPOTENSION

C. F. Scurr, M.V.O., D.A., F.F.A.R.C.S.

\author{
CHLORPROMAZINE AND ALLIED \\ SUBSTANCES \\ John Beard, M.D., D.A., F.F.A.R.C.S., \\ D.C.H. \\ CONTROLLED HYPOTHERMIA \\ E. J. Delorme, M.D., F.R.C.S.(C.) \\ MANAGEMENT OF THE APNOEIC
PATIENT
Ronald Woolmer, D.A., F.F.A.R.C.S. \\ THE USE OF ANTIDOTES IN \\ ANAESTHESIA \\ B. A. Sellick, D.A., F.F.A.R.C.S.
}

Published by

THE FELLOWSHIP OF POSTGRADUATE MEDICINE

60, Portland Place, London, W.1

\section{Index for 1955 is now ready. Have your Journals bound up into a volume NOW. See advertise- ment on page 210 for details.}

